\title{
EL COMERCIO DE LIBROS EN LA GALICIA DEL ANTIGUO REGIMEN'
}

\author{
Ofelia Rey Castelao \\ Universidad de Santiago
}

\begin{abstract}
Resumen. El estudio del comercio de libros y de otros productos de la imprenta durante la Edad Moderna presenta especiales dificultades en ámbitos periféricos como Galicia, ya que generó poca documentación. En este artículo se revisa este problema y se proponen vías alternativas para intentar cubrir esa deficiencia informativa. Se plantean además algunas cuestiones de método referidas a la difusión de la cultura letrada en territorios rurales, poco alfabetizados, bilingües y mal comunicados.
\end{abstract}

Palabras clave: libros, libreros, cultura letrada, comercio.

ABstract. The study of the trade of books and other products of the print during the Modern Age is very difficult in peripheral countries like Galicia; the lack of historical documentation is the greatest problem. In this article, that problem is analyzed and other formulas set out to cover that deficiency of the information. The article raises, in addition, some methodological questions about the diffusion of the learned culture in rural, illiterate, bilingual and bad communicated territories.

Keywords: books, booksellers, learned culture, trade.

EL DESARROLLO alcanzado en los últimos años por la investigación sobre los productos de la imprenta es de tal magnitud que da sensación de vértigo, pero también es verdad que los niveles de calidad alcanzados son realmente altos, algo que no puede

1 Investigación financiada a través del proyecto Comunicación y difusión en la Galicia del Antiguo Régimen: cultura oral y cultura escrita en una sociedad bilingüe, Ministerio de Educación y Ciencia, HUM2005-01289/HIST. 
decirse de otros campos de la historia, y, en apariencia, todos los aspectos han sido abordados. Sin embargo, existe una faceta muy poco investigada: el comercio de tales productos. Esto se debe a que los investigadores de este sector proceden en buen número de la investigación sobre la cultura escrita y a que, por lo tanto, están habituados a trabajar sobre lo impreso como soporte cultural y, desde ese punto de vista, abordan la cuestión clave de la difusión de lo escrito y de lo impreso, centrada en lo inmaterial a partir de una base teórica a la que se le ha dedicado una enorme atención. Pero la especialización implica en no pocos casos el desconocimiento del contexto histórico de esa difusión y, con más frecuencia, el olvido de cómo se producía la difusión en términos materiales - exclusión hecha de los estudios sobre libreros y librerías-. Sin embargo, es una cuestión de la máxima relevancia porque, obviamente, los precios bajos, la rapidez y la universalidad que la imprenta dio a la producción escrita, no implicaron que la clientela potencial de sus productos creciera bajo los mismos supuestos, sino que esos productos tuvieron que llegar a sus destinatarios en un contexto comercial en el que el transporte no era barato, ni rápido, ni universal, y, dado que pesaban y tenían un formato poco adaptable, es este un elemento que no puede desdeñarse. Dicho de otro modo: en la investigación se estudian imprentas e impresores, librerías y libreros, bibliotecas y lectores, pero apenas se presta atención a los pasos intermedios, lo que deja sin respuesta preguntas respecto a cómo, por ejemplo, nos podemos encontrar en el inventario de una biblioteca de provincias un libro publicado a miles de kilómetros, escrito en un idioma exótico y sobre un tema perfectamente prescindible.

Pero la observación de la difusión en términos de mercado siempre tiene el problema de las fuentes, sobre todo cuando se desciende al nivel más bajo de buhoneros o trajineros y al de los productos de menor precio. Y si hallamos referencias a este tráfico, muchas veces no pasan de ser genéricas, de modo que se habla de fardos o de atados de libros, incluso de arrobas, pero no de títulos o volúmenes, y raras veces se dan cifras sobre el coste de transporte. Estas deficiencias afectan más a los mercados provinciales y especialmente a los de territorios periféricos alejados de los centros de producción o de distribución, ya que cuanto menos importantes eran las partidas de impresos, más se diluían documentalmente entre las otras mercancías; de modo que la investigación sobre los ámbitos provinciales, ha de rendirse ante la evidencia de que son los menos documentados, pero no por eso los menos interesantes, ya que eran mayoritarios al fin y al cabo y porque, siendo su producción impresa generalmente pobre en cantidad y calidad, e insuficiente para satisfacer a los clientes locales, eran mercados dependientes a donde los productos de la imprenta llegaban con el sobreprecio del transporte ${ }^{2}$.

2 Nos ocupamos de estos problemas en "Lectores y libros en tiempos del Quijote", Revista Pedralbes, $\mathrm{n}^{\circ} 25,2005$, pp.103-131; "Libros y lectura en Galicia a comienzos del siglo XVII: la difícil di- 
Más allá de que la difusión de los contenidos es lo realmente relevante, lo cierto es que los contenidos dependen en gran medida del soporte físico: sin ir más lejos, la permanencia del manuscrito y la trascendental importancia de la transmisión oral no impiden ver que ambos medios son insuficientes, el primero por su incapacidad de generar copias en la misma medida que la imprenta y el segundo porque no puede sustituir a las imágenes impresas o porque simplifica o altera los mensajes complejos. En fin: sean libros, folletos, periódicos, hojas sueltas... hablamos de objetos, frecuentemente pesados e incómodos de transportar y su tráfico apenas se deja ver en fuentes que informan de aspectos distintos y que carecen de continuidad formal y de una representatividad aceptable. El hecho mismo de que podamos medir las existencias de impresos en librerías y bibliotecas privadas e institucionales, ya es muy positivo, incluso teniendo en cuenta que lo reflejado en los inventarios depende muchas veces del valor económico de lo inventariado y de su fungibilidad. Los historiadores podemos saber dónde, cuándo o cómo se producían los impresos y cuáles eran las formas y contenidos de estos, $\mathrm{y}$, en el otro extremo, cuántos y quiénes los tenían y las formas y contenidos de lo que tenían, pero es difícil saber cómo los impresos hacían el tránsito entre esos dos extremos y aún dando todos los pasos correctamente, sólo constatamos existencias o ausencias. La resolución de ese tránsito tiene un elemento importante en los libreros, pero es evidente que los estudios -muchos, por ciertodonde se analiza una localidad en todos los niveles -impresores, libreros, poseedores de libros-, revelan siempre serias diferencias entre lo que producen los impresores y lo que almacenan los libreros, y entre esto y lo que se guarda en las casas o se custodia en las bibliotecas, incluso cuando se trata de libros producidos y comercializados en un breve espacio de tiempo; es decir, las diferencias entre libreros y poseedores de libros son comprensibles en el sentido de que estos tienen muchas veces acumulaciones ajenas a su voluntad como adquirentes, pero son más difíciles de explicar cuando se trata de publicaciones recientes.

Finalmente, no olvidemos que el comercio de los productos de la imprenta está sometido a reglas económicas puras y duras en términos de oferta y de demanda, medios de pago, precios de transporte, etc. Curiosamente, como lo que se comerciaba tenía un valor cultural, el estudio de todos esos elementos se transforma en el estudio de las prácticas culturales y de su funcionamiento, lo que equivale a observar la función de los productos impresos como catalizadora del desarrollo socio-cultural de

fusión del Quijote en las periferias culturales”, en GOY, A. y PATIÑO, C.: El tapiz humanista, Santiago, 2006, pp. 251 a 274; "A cultura escrita en Galicia. Séculos XVI-XVIII”, Entre liñas. Unha ollada á historia da cultura escrita en Galicia, Ourense, 2006, pp.79 a 122; “A vueltas con la difusión de impresos en la Edad Moderna”, Homenaje a Baudilio Barreiro, A Coruña, 2007 ( en prensa). 
una ciudad, una comarca, un país..., por cuanto el intercambio crea un proceso en cadena que genera nuevas ideas, difunde modelos o genera tradiciones. Por eso mismo, no podemos ignorar que en 1743, el benedictino Padre Sarmiento, exponía su interés en que se introduzca en Galicia un Comercio Literario: dudaba qué comercio estaba por entonces más atrasado en Galicia, pero tenía la certeza de que el Comercio Civil y de Géneros en las naciones, se funda en el Comercio Literario. Así pues, por este se debe comenzar en Galicia antes de pensar en otros Comercios. Como buen conocedor de la realidad gallega, era consciente de la debilidad de este tráfico, aunque sus ideas para solucionarla no andaban atinadas, ya que lo fiaba todo a la fabricación de papel y a una cadena productivo-mercantil que se iniciaba con romper la dependencia del suministro desde fuera de modo que el papel que no se pudiere vender en blanco, se vendería en libros; conseguido esto, por la proporción que tienen en Galicia de comunicarse con todo el Mundo, sería fácil extraer muchos libros para la venta. Lo principal habia de ser reimprimir los libros que ya son muy raros, y los que son muy precisos... También así saldrá menos dinero de Galicia a título de libros chabacanos... ${ }^{3}$ El programa de Sarmiento no se imprimió y de él sólo vale su capacidad de sugerir una salida económica para su tierra y de enlazar la economía con un "mercado cultural", pero falla por su confianza extrema en las condiciones naturales de Galicia y en la laboriosidad de los gallegos -anuladas por el problema casi irresoluble de la escasa y sesgada demanda interna de productos de la imprenta- y en la ingenua conversión en intermediarios culturales de quienes intervenían en el proceso mercantil, lo que encajaría mal con aquellos trajineros, analfabetos quizá, que en los lomos de sus recuas transportaban de Madrid a Compostela, gruesos tratados en latín de teología o de derecho...

\section{Repasando lo obvio}

El caso de Galicia, típico de las culturas periféricas, puede servirnos otra vez para incidir en que, más allá de los grandes centros de producción y comercio de libros, es preciso atender a estos otros ámbitos en los que se daban cita todos los obstáculos para una difusión fluida de los productos de la imprenta. Recordemos que el intercambio de estos productos tiene un mecanismo de transmisión básico, el de la vecindad o proximidad en sus diferentes escalas. En un territorio como Galicia, con más de un $90 \%$ de población rural organizada en un hábitat denso y disperso, la difusión de información se produce de modo lento pero continuado -de persona a persona, de

3 Manuscrito de 1743 titulado "Fábricas y distinción de papel"; reproducido por GAYOSO CARREIRA, G.: "El P. Sarmiento y el papel”, Estudos adicados a Fr. Martín Sarmiento, Santiago, 1995, p. 182. 
aldea en aldea-, que se resiente de la debilidad de las ciudades, espacios donde lo hace rápidamente y no por vecindad: en 1591, solo un 10 o $12 \%$ de la población gallega vivía en núcleos de más de mil habitantes y en 1753 sólo un $5 \%$ en núcleos de más de dos mil. Faltaba además una red urbana densa, comunicada y sobre todo, jerarquizada y complementaria, con lugares puente o redistribuidores, salvo las pequeñas villas, esenciales en la difusión entre las ciudades y el campo. En las villas y ciudades gallegas radicaban la mayor parte de los servicios y productos culturales y allí vivían las elites -todo el alto clero secular y tres cuartas partes de los frailes y monjes, una cuarta parte de los nobles e hidalgos, casi todos los comerciantes y profesionales liberales, funcionarios y administrativos-, y la mayor parte de los artesanos, y eran núcleos con mayor diversificación socio-profesional que los rurales, de modo que recibían más información y generaban modos y hábitos culturales que influían en el resto de la sociedad; pero en Galicia se notan la falta de verdadera diversidad socio-profesional entre los distintos núcleos -a pesar de los cambios ostensibles vividos por A Coruña y Ferrol en la segunda mitad del siglo XVIII- y la debilidad de las poblaciones flotantes -militares, clérigos, nobles, profesores, artistas, etc.-, transmisores efectivos de información y de productos culturales. Debe tenerse en cuenta que la diversidad era un mecanismo básico de la difusión, en especial la de aquellos libros minoritarios que solo tenían interés directo para algunos individuos y entre quienes la difusión era rápida en el interior de esa minoría y lenta o inexistente entre la mayoría, aunque esta pudiera beneficiarse de esa circulación, como sucedía con el libro científico, jurídico o artístico, que sólo interesaba a los profesionales o a un sector curioso.

Las comunicaciones ágiles podían actuar como correctoras de las deficiencias de ese tipo, pero el aislamiento de Galicia por tierra hacía que el suministro de libros fuese irregular y costoso, $\mathrm{y}$, dado que las mejoras en la comunicación terrestre fueron poco relevantes, los productos de la imprenta llegaron en todo momento a lomos de recuas. La comunicación por mar no fue decisiva en el aspecto que tratamos: el transporte a precios más baratos que por tierra solía facilitar la transmisión cultural a quienes vivían en zonas litorales, pero los núcleos fundamentales de los que se surtía Galicia estaban situados en el interior peninsular -Valladolid, Medina del Campo, Salamanca y sobre todo Madrid- y las ciudades gallegas de mayor importancia y consumo se situaban en la zona más occidental, de modo que los libros no solo tenían que llegar a Galicia, sino que la recorrían de Este a Oeste antes de llegar a su destino. El transporte marítimo valía para los libros de los Países Bajos o de Francia, pero sólo se aprovechó ocasionalmente ${ }^{4}$. A cambio, la extensa costa gallega era incontrolable por la Inquisición o por los poderes públicos, aunque no parece que se hubiera

4 No tenemos noticia de que se hubiese empleado con Sevilla. 
utilizado de modo habitual para hacer entrar libros e impresos prohibidos. En términos de transmisión de productos culturales, las fronteras con otros países no fueron de gran relevancia por lo general, aunque pudieran actuar como desfiladeros de lo nuevo o de lo prohibido, pero en el caso gallego, la frontera con Portugal, siendo amplia y muy permeable, fue poco útil porque en materia de producción impresa este era también un país dependiente y sus productos -en formas y en contenidos- eran coincidentes con los españoles 5 .

Determinantes en la lentitud y en la debilidad del mercado eran, obviamente, los bajos niveles de alfabetización, junto con el predominio del idioma gallego entre la inmensa mayoría de la población, lo que dificultaba su acceso a la lectura. En este territorio, como en otros con una lengua diferente del castellano y de constitución muy rural, los núcleos más alfabetizados eran los urbanos y en estos era donde el castellano estaba más presente -al menos entre los poderosos-, de modo que entre las distantes villas y ciudades gallegas se extendían amplias zonas analfabetas y gallego-hablantes: Galicia tenía 735.000 en 1631, fecha en la que los cálculos más altos para la mayoritaria población rural, sitúan en 6-7\% el número de varones adultos que sabían firmar; en el contexto de una población bastante más numerosa -1.299.213 en 1752 y 1.345 .805 en 1787 -, los cifras rurales están en torno al $20 \%$ de firmantes masculinos a principios del XVIII - con diferencias del 13\% al 34\%- y 40\% a finales -del $17 \%$ al 60\%-. Esas tasas eran siempre más altas y de crecimiento rápido en la costa y en los valles -en tierras ricas, bien pobladas y bien comunicadas- y más bajas y lentas en zonas de montaña, de economía de subsistencias, poco pobladas y alejadas de las vías de comunicación. La alfabetización urbana da mejores cifras: en 1635, en las ciudades occidentales firmaba el $19.7 \%$ de los jefes de familia -sin contar pobres ni eclesiásticos, con fuertes diferencias -30\% en Vigo o Baiona, 5.5\% de Noia-; Santiago, la ciudad con mejor dotación educativa, tenía un $28 \%$ de firmantes $-52.5 \%$ si se incluye al clero-, pero las diferencias sociales eran muy acusadas: firmaba el $91.8 \%$ de los notables compostelanos, el 6-7.5\% de los pequeños contribuyentes, 20\% de los medianos y 50\% de los ricos; en 1753 con 17.000 habitantes, firmaban todos los eclesiásticos, hidalgos, comerciantes y profesionales liberales; entre los artesanos (40\% del vecindario), lo hacía un $40 / 45 \%$ en $1760 / 1761$ y el $58.3 \%$ hacia 1800 , pero había grupos muy alfabetizados -los artesanos de objetos de lujo-, frente a otros muy analfabetos ${ }^{6}$.

5 REY CASTELAO, O.: "Intercambios culturais entre Galicia e Portugal na Idade Moderna", en HERNÁNDEZ BORGE, J. y GONZÁLEZ LOPO, D.L.: Pasado e presente do fenómeno migratorio galego en Europa, Santiago, 2007, pp. 85-116.

6 REY CASTELAO, O.: "Niveles de alfabetización en la Galicia de fines del Antiguo Régimen", Bulletin Hispanique, 1998, pp. 271 a 311. 
En fin, el problema del comercio de libros en Galicia remite al reducido número de los lectores potenciales, pero sobre todo al más reducido aún de los compradores reales. Esa imagen tan poco positiva revela los límites de una minoría letrada, no aquella que sabía leer sino la que podía tener libros en sus casas. Las bibliotecas privadas urbanas del siglo XVI -las mejor conocidas- eran pocas, con pocos libros y con un contenido de baja calidad, abundantes textos religiosos, algo de historia y una fuerte tendencia a responder a las necesidades de oficio de sus poseedores. En los siglos XVII y XVIII había libros en un 30\% de las casas de las que se hizo inventario en Compostela, cifra mal repartida por sectores sociales, pero no hubo grandes colecciones, si bien en esto no hay diferencias con otros ámbitos periféricos. Menos libros había aún en el mundo rural: en la Tierra de Santiago durante los siglos XVII y XVIII sólo se encuentran en una de cada cien casas ${ }^{7}$.

Como es obvio, el mercado gallego no era amplio, habida cuenta de las bajas tasas de alfabetización y de la escasez y pobreza de los núcleos urbanos, y porque a todos los inconvenientes propios, se le añaden los del contexto español, en todo momento caracterizado por una industria incapaz de hacer grandes ediciones de difusión internacional, o incluso reediciones y traducciones, y de hacer sombra a la superioridad empresarial francesa o flamenca, y amputada por los monopolios de impresión, como el de cartillas o abecedarios concedido a la catedral de Valladolid y otros no muy productivos pero sí perjudiciales para quienes no los tenían, todo lo cual favorecía la importación ${ }^{8}$. Así pues, Galicia fue siempre dependiente de la importación dentro de un mercado, el español, también dependiente. Una vez terminado el Concilio de Trento (1563) que fijó los textos normativos y litúrgicos de la Iglesia, la imprenta sólo resistió en Santiago y los impresores compostelanos quedaron reducidos a una clientela local muy limitada, y sólo produjeron textos menores, folletos u hojas sueltas; de 1600 a 1800 se conocen unos 750 impresos compostelanos, de escasa entidad material, tiradas cortas, tamaños pequeños, en castellano, y de contenido religioso o eclesiástico en un 70\%. Todo lo demás llegó, durante los siglos XVI a XVIII, del exterior. Internamente había un modesto trasiego entre particulares -herencias, donaciones, almonedas-, especialmente valioso cuando se trataba de individuos que habían comprado libros durante estancias fuera de Galicia o de foráneos que se habían asentado

7 GELABERT, J.E.: "Lectura y escritura en una ciudad provinciana del s. XVI: Santiago de Compostela", Bulletin Hispanique, 1983, p. 276 y "La cultura libresca de una ciudad provincial del Renacimiento: Santiago de Compostela”, en EIRAS ROEL, A. (Ed.): La Documentación notarial y la Historia, Santiago, 1984, vol. $2^{\circ}$, p. 147. BARREIRO MALLÓN, B.: "Las clases urbanas compostelanas en el siglo XVIII: definición de un estilo de vida y de pensamiento", La Historia social de Galicia, Santiago, 1981, p. 473 y 474.

8 PELIGRY, CH.: "Les difficultés de l'édition castillanne au XVIIe siècle à travers d'un document de l'époque“, Mélanges de la Casa de Velázquez, 1977, p. 257. GAILLAT-FERNÁNDEZ, M. : Les espagnols à Paris à l'époque de Philippe III (1598-1621), Paris, 1997. 
en este reino. Los libreros locales fueron pocos y no especializados hasta fines del XVII, mediocres en existencias de libros y en su capacidad comercial y sin posibilidades de competir, de modo que la mayor parte de los libros llegaban por medio de mercaderes o de transportistas que traían los pedidos hechos a libreros e impresores del resto de España o del extranjero.

En este contexto, Santiago tuvo que haber jugado un papel redistribuidor, dado que no sólo era la única ciudad con imprenta en toda Galicia, sino que fue la única que hasta la segunda mitad del siglo XVIII tuvo libreros. En general no está bien estudiada la función redistribuidora que ciertos núcleos urbanos, grandes o pequeños, ejercieron sobre amplios territorios, en especial en las zonas periféricas 9 ; no hay muchos datos para poder hacerlo, pero con frecuencia los tamaños y características de las librerías de esos núcleos eran mayores y diferentes a los esperables en su mercado potencial más inmediato. Hoy en día, se conoce bastante bien la jerarquía redistribuidora de Andalucía, con Sevilla en la cúspide ${ }^{10}$, controlando toda la zona occidental y el mercado americano, y con Granada en la zona oriental, al menos en el siglo XVI, ya que desde 1560, grandes y buenas librerías surtían a la ciudad y a un amplio territorio en el que se situaban núcleos como Baeza, convirtiéndose en un centro redistribuidor cuyas librerías contaban con los listados más avanzados que se conocen en los ámbitos provinciales de esa época ${ }^{11}$. Se da la circunstancia de que Santiago tenía una constante relación con Granada, ya que allí tenían el arzobispo y cabildo compostelanos la administración del Voto de Santiago, cuyo movimiento económico atrajo a un buen puñado de mercaderes y generó una densa relación comercial con Galicia que quizá incluyera libros. Con más razón, fue esencial la vinculación de Compostela con el gran centro redistribuidor del mercado norteño, Valladolid-Medina del Campo, con el que Santiago estaba unida por idénticas razones, además de estar mucho más próximo, evidentemente ${ }^{12}$. No ha de

9 PEÑA DÍAZ, M.: "El comercio, la circulación y la geografía del libro", en INFANTES, V., LOPEZ, F. Y BOTREL, J.F.: Historia de la edición y la lectura en España, 1472-1914, Madrid, 2003, pp. 85-93.

10 GONZÁLEZ SÁNCHEZ, C.A: Los mundos del libro. Medios de difusión de la cultura occidental en las Indias de los siglos XVI y XVII, Sevilla, 1999. GONZÁLEZ SÁNCHEZ, C.A. y MAILLARD ALVAREZ, N.: Orbe tipográfico. El mercado del libro en la Sevilla de la segunda mitad del siglo XVI, Gijón, 2003.

11 OSORIO PÉREZ, M.J. y otros: Trastiendas de la cultura: librerías y libreros en la Granada del siglo XVI, Granada, 2001, p. 561 y ss.

12 ROJO VEGA, A.: "El negocio del libro en Medina del Campo", Investigaciones históricas, 1988, p. 18; "Comercio e industria del libro en el noroeste peninsular. Siglo XVI", en LÓPEZ-VIDRIERO, M.L. y CÁTEDRA, P.: El libro antiguo español, II, Salamanca, 1992, p. 425; Impresores, libreros y papeleros en Medina del Campo y Valladolid, siglo XVII, Valladolid, 1994. DADSON, T.J.: Libros, lectores y lecturas, Madrid, 1998, p. 31. Por lo general, las librerías castellanas del XVI eran pequeñas, pero en centros reemisores como Medina del Campo, se daban medidas muy superiores; BECARES, V.: La librería de Benito Boyer, Medina del Campo, 1992; WAGNER, K.: "Les librairies espagnols", en BARBIER, F.: L'Europe et le livre. Réseaux et pratiques du négoce de librairie, XVIe-XIXe siècles, París, 1996, p. 96 y ss. 
desdeñarse, sin embargo, el papel importantísimo jugado por Salamanca al menos hasta fines del siglo XVI, de donde los libreros compostelanos se surtían, como se observa a través del trato entre el librero compostelano Geraldo del Sol y el salmantino Matías Ghast a mediados de ese siglo, o el existente entre el librero compostelano Agustín de Paz y varios libreros salmantinos en los años sesenta, o entre Cornelio Binan y el librero compostelano Pedro de Nandín en los ochenta ${ }^{13}$. La relación con Salamanca queda certificada además por la concurrencia de libreros salmantinos como los Junta o los Canova, en tasaciones y recuentos, a demanda fundamentalmente del cabildo catedralicio ${ }^{14}$. Esto no obsta para que de otros centros y procedencias llegaran libros pero, por hacerlo a través de mercaderes no especializados, es imposible conocerlos, aunque todos fueran barridos por Madrid desde comienzos del siglo XVII.

\section{Lo que sabemos}

Como mercado dependiente, Galicia se suministrada por las vías convencionales, difíciles de conocer, como ya se dijo. La ausencia de noticias sobre "colporteurs" o buhoneros no impide pensar que hubiera un mercado de ese tipo, más o menos legal -algo común a toda Europa ${ }^{15}$-, que sirviese sobre todo a la circulación de impresos baratos y fáciles de transportar. Se ha podido constatar que los "mercadillos" de las misiones populares constituyeron una vía de comercialización de libros de ese tipo, pero de tema casi solo religioso; así, por ejemplo, el padre Tirso González Santalla, tras su misión en Monforte, comenta que "porque los libros espirituales importan tanto para conservar e introducir el fervor, y allí no los había, moví a un hidalgo rico a que enviase a su costa por alguna cantidad de los ejercicios espirituales de N.S.P. Ignacio por el P. Salazar y de Villacastines y por docientas máximas de eternidad. También moví a muchos a comprar la vida de San Francisco Javier. Y porque don Sebastián de Arce se hizo llevar a Lugo cien vidas y no pudo despachar allí sino como dos docenas, hize que despachasen en Mondoñedo otras dos docenas y que enviasen a Monforte cincuenta para allí y para Orense"16. Sin embargo, ese comercio no parecía apropiado a otros de los misioneros que anduvieron por Galicia, como el padre Caravantes quien

13 GELABERT, J.E.: "La cultura libresca...,", p. 148.

14 Sobre los salmantinos Junta, Cánova, Gast y otros que aparecen en Santiago, MANO GONZÁLEZ, M.: Mercaderes e impresores en la Salamanca del siglo XVI, Salamanca, 1998, p. 91 y ss.

15 CHARTIER, R. y LUSENBRINK, H.J. (Dirs.) : Colportage et lecture populaires. Imprimés de large circulation en Europe, XVIe-XXe siècles, París, 1996, en especial los artículos de R. Chartier, p. 11, y L. Fontaine, p. 21; también, BOLLÉME, G.: "Literatura popular y comercio ambulante del libro en el siglo XVIII”, en PETRUCCI, A.: Libros, editores y público en la Europa moderna, Valencia, 1995, p. 297.

16 REYERO, E.: Misiones del M.R.P. Tirso González de Santalla. XIII prepósito general de la Compañia de Jesús, 1675-1686, Santiago, 1913, p. 497. 
consideraba importante "para la permanencia y aumento del fruto de la predicación, llevar los misionarios algunos quadernitos impresos, breves y vivos" sobre la contrición, la comunión, la confesión, la devoción a la Virgen...; si bien entendía que no había dificultades de suministro "pues los señores obispos suelen costear la imprenta" o el impresor se encargaba de eso "sin que los misioneros intervengan más que en el ajuste de la imprenta y disposición de lo que se ha de imprimir"17.

Entre las vías convencionales es preciso enumerar la circulación entre particulares, muy importante, pero que no necesariamente tenía un coste: así sucedía con las donaciones o las cesiones por herencia. A un coste diferente del propio del mercado, los libros que se vendían en las almonedas públicas o las muy peculiares que se realizaban en los conventos y monasterios, de las que luego hablaremos. A las almonedas post-mortem concurrían particulares ${ }^{18}$, pero también instituciones, como la Universidad: sirva como ejemplo la iniciativa tomada en 1728 por el rector del Colegio de Fonseca, quien, argumentando que la última visita ordinaria "havía repetido el coste de libros que avía tomado en las almonedas que se hicieran por muerte", se habían adquirido libros en las efectuadas tras la muerte del arzobispo don Miguel Herrero y Esgueva y del Dr. don Pedro A. de Aldao ${ }^{19}$; en 1734 se decide comprar por 3.063 reales un lote de libros en la almoneda del doctoral del cabildo, don Pedro Freire de Andrade, quien por vía testamentaria había legado a la Universidad trece tomos y quinientos reales para su empleo en libros ${ }^{20}$; en 1738 se compraron por 1.883 reales algunos más en las almonedas del arzobispo don José del Yermo y otros en la del Dr. don Francisco de la Huerta, ambas en Santiago, y en la de don Pedro Canel, en Mondoñedo, a donde se envía a un comisionado, ya que "por ser de entidad, en ella abería algunos juegos o thomos que con combeniencia pudiesen servir en la Universidad"21.

Las ventas de bibliotecas enteras no fueron raras. En ocasiones se trataba de individuos que por alguna razón quisieron vender las suyas propias, tal es el caso en 1796 de los libros del obispo de Blois, refugiado en España, cuyos fondos constaban en una lista "con la tasa hecha por Sancha", y que fue comprada por la Universidad en 16.000 reales. En otras, se trataba de instituciones que querían deshacerse de ellas, como fue el caso de cabildo catedralicio, que en 1567, vendió la biblioteca de don

17 Práctica de misiones, Lib. I, p. 139.

18 Véase los datos en REY CASTELAO, O.: Libros y lectura en Galicia. Siglos XVI al XIX, Santiago, 2003, p. 156 y ss.

19 "Los que tenían entrados en la librería de esta Universidad" y habían costado 989 rs. Claustro de 24-V-1728, Archivo Histórico de la Universidad de Santiago (en adelante A.H.U.S.), Universidad, Serie Histórica, libro A130.

20 Claustro de 28-IV-1734, A.H.U.S., Universidad, Serie Histórica, libro A131.

21 La referencia a la librería de Yermo aparece en libranza de 1-VI-1738, A.H.U.S., Universidad, Serie Histórica, libro A33, y las otras en ib. id., libro 132, claustros de 31-V y 17-VII-1738. 
Pedro Medina, y tras heredar la del obispo auxiliar don Bernardino Carmona, tasada en 1.240 ducados, la cedió en 1572 a la Universidad en más de mil ducados ${ }^{22}$; a comienzos del siglo XVII se deshizo de los libros donados por el arzobispo don Maximiliano de Austria y por el historiador Castellá Ferrer, y continuó con esa práctica en otras ocasiones. También el cabildo de Mondoñedo vendió en 1580 al obispo de Oviedo la biblioteca que le había donado el prelado mindoniense don Gonzalo de Soterrano, y en esa misma época vendió la heredada del cronista Lic. Molina ${ }^{23}$, etc. Por esa vía, obviamente, se iban incorporando a la circulación, libros que en muchos casos había llegado del exterior por mano sobre todo de eclesiásticos foráneos que vivieron en Galicia durante un tiempo o por la de gallegos que habían estado fuera.

En lo que atañe al comercio propiamente dicho, Santiago de Compostela, como pequeño centro de re-distribución dentro de otro mercado de redistribución, es sin duda un caso representativo de la amplia franja septentrional. Los impresores compostelanos de los siglos XVI y XVII también vendían libros y otros productos, y eran encuadernadores o componedores de libros, de modo que la aparición de los libreros en sentido estricto fue tardía ${ }^{24}$. Gracias a documentación esporádica, pueden hilvanarse algunos elementos de su trabajo y, a su vez, de su modo de suministro. Así, por ejemplo, sabemos de la importante actividad del librero compostelano Geraldo de Sol, quien compraba libros en Salamanca, como ya se dijo, y otros procedentes de Francia (Burdeos, Toulousse) y de Flandes ${ }^{25}$; sus compras salmantinas revelan que los clásicos grecolatinos eran la clave, por lo que se deduce que sus clientes eran quienes dominaran el latín -clérigos y juristas-, lo que se corrobora con el 20.1\% de los volúmenes de tema religioso y el $14.5 \%$ de textos jurídicos; $8.7 \%$ de "literatura renacentista", $6.8 \%$ de libros de moral, $4.6 \%$ de textos filológicos, $2.6 \%$ de música, $1.4 \%$ de geografía y un $8.7 \%$ de otros temas, componen su otra oferta. El impresor Luis de Paz, que también vendía libros, tenía 1.208 volúmenes en 1564, más de un tercio de derecho civil y canónico (35.3\%) destinados a la clientela estudiantil universitaria, y casi otro tercio de breviarios y libros litúrgicos para la clientela clerical; 12.6\% de clásicos grecolatinos, poca literatura, algo de historia y geografía, etc., revelan una librería bien surtida en número de libros y en contenidos, pero el hecho de que su dueño sólo fuera impresor ocasionalmente, revela a su vez que la importación de impresos era esencial en Santiago. El

22 LÓPEZ FERREIRO, A.: Historia de la S.A.M. Iglesia de Santiago, Santiago, 1905, p. 239.

23 CAL PARDO, E.: Mondoñedo. Catedral, ciudad, obispado, Mondoñedo, 1992.

24 En la visita de librerías de 1572 no consta que los hubiera o no se identificaron (GARCÍA ORO, J. y PORTELA, M.J.: Felipe II y los libreros: actas de la visita a las librerías del Reino de Castilla en 1572, Madrid, 1997).

25 Geraldo del Sol aparece en 1541 firmando una obligación a favor de Sancho de Mena, de Toulouse, y de Juan de Gaona, por 45.000 mrs. que les debía de libros y otras mercancías. En 1553 hace un encargo al mercader Juan Flamenco, de A Coruña. GELABERT, J.E.:"Lectura y escritura...", p. 276; y "La cultura libresca...", p. 147 
inventario de la librería de Alonso Díaz, realizado en 1627, demuestra que este librero vendía libros nuevos o usados, pero también papel y hacía encuadernaciones; tenía 341 ejemplares de formatos grandes y 5.933 pliegos sueltos o folletitos, previsibles y polarizados, en tanto que contenían productos para un sector selecto de la ciudad, y otros menos sofisticados -comedias, "historias", "pronósticos", "libros de secretos", "entretenimientos de damas", vidas de santos- o instrumentales -textos litúrgicos-, de bajo precio y clientela potencial amplia ${ }^{26}$, pero en todo caso es una librería que, comparada con las de Madrid de esos años, sorprende en una ciudad de provincias ${ }^{27}$. El vacío documental del XVII no nos permite ir más allá.

En el siglo XVIII, los datos son algo más abundantes y positivos. Sabemos, por ejemplo, que en 1718, el impresor y librero compostelano Antonio Pedache "intentaba hazer viaje a León de Francia a algunas dependencias", por lo que se puso en contacto con el claustro universitario "por tener noticia de que la Universidad quería hazer empleo de libros en dicha ciudad", ofreciéndose como intermediario; su propuesta fue aceptada, dándosele por el claustro cuarenta mil reales y un poder para hacer esa compra, pero la operación no fue un éxito, y acabaría en los tribunales por incumplimiento del acuerdo por parte de Pedache; a fines de 1720 se abona a Pedro Stafford el flete del barco que había traído los libros al puerto de A Coruña, se solicita permiso a la Inquisición para abrir los fardos y estos se llevan a Santiago, pero aún se mantuvieron por un tiempo los problemas con el librero por el exceso de costo de la operación y la negativa de la Universidad a abonar el incremento ${ }^{28}$, lo que revela el excesivo riesgo asumido por Pedache. No tenemos más noticias de este tipo, y todo indica que la vía madrileña era la más segura.

En comparación con los siglos anteriores, el cambio es notable a mediados del setecientos, en cualquier caso. En 1753 había en Santiago cuatro mercaderes de libros -los únicos de Galicia aún ${ }^{29}$-, con utilidades fiscales que iban de los 660 reales de Ma-

26 Publicado por CASTRO, M. de: "Inventario de un librería de Santiago a comienzos del s. XVII", Cuadernos de Estudios Gallegos, 1968, p. 313. Véase nuestro análisis en Libros y lectura en Galicia..., p. 234.

27 En 1629, en Madrid la del librero Miguel Martínez, se valoró en 27.296 rs. y contenía 5.258 vols. (DADSON, T.J.: "La librería de Miguel Martínez (1629). Librero y editor del primer tercio del siglo XVII", Les livres des Espagnols, p. 41).

28 A.H.U.S, Universidad, Serie Histórica, libro A129, claustros de 2-12-1718 a 12-2-1721, diversos folios. Entre las libranzas, en 22-IX-1720 aparece una en la que se pagan 462. rs. a los carreteros que transportaron de A Coruña a Santiago 17 fardos de libros en 14 carros; en claustro de 22-XI-1720 se aprueba el pago de 252 pesos por el flete. Todo lo cual indica que las cifras previstas se superaron y que de ahí procedieron las diferencias con el librero.

29 El Juez de Imprentas, preocupado por la existencia de libreros en Tui y su provincia por la cercanía de Portugal, preguntó al respecto a la Junta del Reino de Galicia, que informasen de que sólo en Santiago había librerías (LOPEZ, F.: "Un aperçu de la librairie espagnole au milieu du XVIIIe siècle", De l'alphabétisation aux circuits du livre en Espagne, XVIe-XIXe. siècles, París, 1987, p. 407). 
nuel de Cascallana hasta los 5.000 reales de don Manuel Vasualdo -en medio, doña Josefa María Díaz con 2.400 y Bernardo Reino, 1.650-30, y un mercader forastero cuyos emolumentos se evaluaron en 3.500 reales y que no se dedicaba sólo a los libros; otros mercaderes negociaban libros y los incluían dentro de la denominación genérica de sus mercancías, como don Benito Tojo y Castro, cerero, tendero de grosura y mercader de vino, que en actas notariales aparece vendiendo $\operatorname{libros}^{31}$. Ya en la segunda mitad del siglo aparecen librerías en otros núcleos como A Coruña, donde en 1795, don Manuel Soto, maestro librero, recontó la de don Vicente Gutiérrez ${ }^{32}$, integrada por 4.427 volúmenes de 1.440 títulos -tasados en unos 43.000 rs-, en los que la literatura de cordel era minoritaria -romances, sainetes, comedias y estampas-, pero era muy amplio el sector religioso, algo llamativo en una ciudad en pleno auge económico y con una importante burguesía mercantil.

Las instituciones se suministraban habitualmente en el exterior, en Salamanca en gran medida en el XVI y desde fines de ese siglo hasta el XIX, en Madrid, de donde los libros venían la mayor parte de las veces confundidos entre otras mercancías de lujo que se compraban allí. En las contabilidades constan frecuentes pagos a transportistas -maragatos sobre todo- que porteaban las adquisiciones hechas en la Corte; así lo hizo a lo largo de la Edad Moderna el cabildo catedralicio, que adquiría y hacía traer de fuera los libros necesarios para la fábrica, de liturgia casi en exclusiva; el costo de transporte de salterios, oficios, martirologios, etc., contados a veces por arrobas, no siempre se deslinda del costo global de las operaciones, y cuando así sucede suele ser muy oscilante, pero como media se sitúa en el 5\% del precio final, aunque lo habitual, excluyendo partidas muy rebajadas, era superar el $8 \%$ en el XVII, sin que en el XVIII haya costes muy distintos a ese $5 \%{ }^{33}$, pero no son cifras representativas, dado que nos hallamos ante un cliente especial.

La Universidad de Santiago, que tras un largo abandono, desde 1717 inicia la creación de un verdadero fondo de libros, no desdeñaba a los libreros compostela$\operatorname{nos}^{34}$ y recurría a las almonedas, como se ha dicho ${ }^{35}$, pero a medida que avanza el siglo XVIII, se nota cada vez más la importancia de las compras a los libreros de

30 Archivo del Reino de Galicia, Catastro, leg. 2539.

31 Por ejemplo, en 18-IX-1753 firmó un convenio con D. Juan A. Casal, cura de S. F. de Sales, para suministrarle libros por valor de 3.000 rs. que el cura le adelantó (A.H.U.S., Protocolos Notariales, leg. 5562, f. 58).

32 SAMPAYO SEOANE, E.: "La cultura escrita en La Coruña de finales del Antiguo Régimen. Una visión diferente: la librería de Don Vicente Gutiérrez", Obradorio de Historia Moderna, 8 (1999), p. 199.

33 Datos procedentes de los Libros de Fábrica de la catedral.

34 Desde luego, recurría a ellos para la venta de duplicados, como se constata en 1774, cuando el claustro vio las cuentas del librero Gregorio Blanco, quien junto con el bedel había elaborado el índice de los duplicados para su venta.

35 GASALLA, P. y SAAVEDRA, P. en el capítulo correspondiente a la biblioteca en BARREIRO, X.R. (Ed.): Historia da Universidade de Santiago, Santiago, 1998, p. 359 y ss. 
Madrid; en los años setenta, Antonio de Sancha y Bernardo Albera fueron los elegidos para los pedidos realizados por el bibliotecario Valle Inclán por valor de 130.742 rs. ${ }^{36}$; en los años noventa, las compras ordinarias se hicieron a libreros de A Coruña ${ }^{37}$, pero sobre todo en Madrid -Albera y Sancha-, ya porque se hacían mediante listas enviadas allí y a las que los libreros de la Corte respondían haciendo un presupuesto ${ }^{38}$, ya porque eran los libreros los que remitían sus ofertas, o porque algunos profesores de paso por Madrid, enviaban recado de las novedades y se les autorizaba la compra $^{39}$, cuando no iban allí con ese objetivo.

Las fórmulas en las que se basó la incorporación de libros por parte de conventos y monasterios compartían rasgos comunes con esas otras bibliotecas institucionales, como las compras y los donativos, pero existían otras dos variantes que eran exclusivas del clero regular: la incorporación de los libros de frailes y monjes fallecidos y el suministro por parte de las propias órdenes, lo que generaba no sólo un medio seguro de adquisiciones, sino también un sistema de circulación interna constante. Las normas propias de las distintas órdenes coinciden en general en esas fórmulas y sólo hay variaciones en la aplicación. Es evidente que si las compras dependían de la voluntad de hacerlas y de la posibilidad de financiarlas y de las rentas excedentes, el poder acumulativo de los libros de religiosos fallecidos dependía del número de componentes de cada casa y de la voluntad y posibilidades que cada uno de ellos hubiera tenido en vida para hacerse con una librería particular. Como preveían las normas, a la muerte de un fraile o monje se hacía recuento de los libros que tenía en su celda, incorporándose a la librería de la casa los que esta no tuviere y procediéndose con los demás a una subasta, pero esta práctica hubiese degenerado en un inapropiado mercadeo de no haberse impuesto la venta en almoneda a cambio de un "precio espiritual", es decir, en misas, y de no haberse prohibido la venta a laicos ${ }^{40}$; era una fórmula extraordinariamente eficaz de suministro interno por la que se garantizaba que los libros no se perdieran para la institución.

36 Es la cantidad que se les pagó por libranza de 14-VI-1774, a lo que habría que añadirse los costos de transporte desde Madrid abonados a los arrieros maragatos (A.H.U.S.), Universidad, Libros de Archivo, libro A34.

37 En 5-VII-1796 se ve lista de libros de A Coruña y se acuerda comprar los señalados por un valor de $391 \mathrm{rs}$.

38 En 13-XI-1797, por ejemplo, se ven las cartas de don Felipe Albera y don Gabriel Sancha con los precios de los libros de una lista que previamente se habían señalado para su compra, aceptando la oferta del segundo.

39 En 1-XII-1802 se aprueba la lista de libros comprada en Madrid por don Jacobo Ma Parga; en 11-X-1803 se ven los comprados por Fray José A. de Santa María, lector de Teología, en Atocha, etc.

40 Se recuerda en la visita a la que es sometido en 1708 el monasterio de Santa María de Sobrado "que si tomaren a misas o a dinero algunos libros o alhajas, sean de poco o mucho valor, no los puedan trocar ni vender a seglar alguno... y solo les permitimos entre sí trocar o vender los tales libros o alhajas por el tanto o menos de lo que les costó" (Archivo del Reino de Galicia. Privados Eclesiásticos, leg. 813-27). 


\section{Una prueba indirecta: el libro italiano en Galicia}

Las fuentes no dan mucho más de sí y en la mayor parte de los casos no se puede responder cómo un libro llegó a su poseedor, fuese este un particular o una institución. Las distintas vías que se han intentado para atisbar ese recorrido en Galicia -alguna, metodológicamente incorrecta ${ }^{41}$ - nos llevan, finalmente, a constatar presencias y a reafirmar la idea de que la capilaridad en la circulación funciona en este territorio bajo condiciones difíciles, de modo que los libros llegaban sesgadamente -menos por voluntad que por selección impuesta por los distintos obstáculos, fundamentalmente por las deficiencias de la información- a quienes los necesitaban para ejercer una profesión, para obtener conocimientos o para el simple disfrute. Obviamente, las instituciones eran las que tenían más información y recursos para hacerse con libros e impresos y eso explica que en un medio como el que hemos descrito, hallemos una importante presencia de libros extranjeros. Y a este aspecto dedicaremos las siguientes páginas, eligiendo como indicador el libro italiano y su presencia en los anaqueles de las bibliotecas institucionales. Nuestra elección obedece a tres criterios: a) los inventarios de libros privados raras veces dan los datos de lugar y fecha de edición, a diferencia de los inventarios de las bibliotecas colectivas; b) los libros italianos hacían un recorrido muy largo pero llegaban desde un país con el que se tenía una intensa relación por vía eclesiástica y a donde viajaban muchos componentes del alto clero; c) el libro italiano, a pesar de su enorme importancia en el mercado europeo, ha quedado relegado por parte de los historiadores en beneficio siempre del libro francés, considerado este como el verdadero indicador de las corrientes más modernas, de modo que la presencia del libro italiano se juzga, a priori, como redundante del libro español, lo que sin ser falso, no es correcto en materias como las artísticas.

Empezando por el registro más antiguo de la biblioteca de la Universidad compostelana, realizado en 1573, se constata entre sus 546 títulos y 649 volúmenes, la importancia de la producción italiana -las obras filológicas de Lorenzo Valla; la historia humanista (Sabellicus, Foresti, Flabio Biondo o Platina); la literatura "moderna" de Petrarca; textos de predicación (Alberto de Padua), etc. Pero es en la segunda mitad del siglo XVIII cuando esta biblioteca adquiere su verdadera configuración y la documentación nos permite ver que en las copiosas compras de libros realizadas en Madrid a partir de 1772 y orientadas a rellenar las enormes lagunas de este fondo, las ediciones francesas eran el $27.5 \%$ de los títulos -en gran parte, colecciones, de modo

41 DOMERGUE, L.: "Les livres importés en Galice au XVIIIe. siècle", De l'alphabétisation... , p. 431, artículo en el que se presenta a una Galicia muy avanzada ideológicamente en el siglo XVIII al haber utilizado como fuente, los catálogos de la Biblioteca de la Universidad de Santiago elaborados en el siglo XX, sin tener en cuenta ni la fecha de incorporación de los libros a ese fondo, ni su origen. 
que el número de volúmenes apenas alcanza la mitad de ese porcentaje-; pero también revelan que era Italia el segundo país de referencia con el 18.6\% de los títulos adquiridos y una cifra semejante de volúmenes, de modo que siendo los libros españoles otro $18.6 \%$, solo suponían el $6.3 \%$ de los volúmenes. Por esa época, la Universidad recibió varias importantes donaciones ${ }^{42}$, entre las cuales destaca la del escultor y arquitecto gallego don Felipe de Castro: buena parte de los libros de esta donación llegada de Madrid, habían sido comprados por el artista en Roma; por eso mismo, en el inventario parcial que se conserva, de 645 títulos y 804 volúmenes, la tonalidad italiana es dominante, empezando porque el italiano es el idioma extranjero preferente - el $50.4 \%$ de los libros de la primera mitad del XVI, en torno al $30 \%$ entre $1550 \mathrm{y}$ 1750 , el 18.6\% después-, y, claro está, por la procedencia de las ediciones en porcentajes, ya que eran italianas el $47.8 \%$ del total en la primera mitad del XVI, el $54.8 \%$ en la segunda, $41 \%$ en la primera del XVII y $25.1 \%$ en la segunda y el $40.9 \%$ entre 1700 y 1750 , descendiendo luego al $22.5 \%$; en total, el $38.1 \%$ de los libros, frente al $14.7 \%$ de Francia y al 32.4\% de España, siendo lo demás o de los Países Bajos o de otros orígenes minoritarios. La donación incluía muchas obras italianas de medicina (Vesalio o Lancisi), fisonomía (Giovanni B. della Porta), monedas y medallas (G. Simeoni, C. Landi, etc), descripciones de los hallazgos arqueológicos de Roma y Herculano de mediados del XVIII ${ }^{43}$-; los grabados de Leonardo da Vinci y los tratados de arquitectura de Vitrubio, Vignola, Serlio o León B. Alberti; de pintura (Leonardo da Vinci, Ciocchi, Bisagno, León B. Alberti, A. Lupis), escultura (F. Orsini y A.F. Doni), emblemas (Alciato); varias ediciones de la obra de Vasari, la biografías de Miguel Angel de Ascanio Condivi (Florencia, 1746), las de pintores boloñeses de C.C. Malvasia, etc.; lecciones magistrales de la Academia del Disegno de Florencia; historia humanista y renacentista (Leonardo Bruni, Flabio Biondo, Navagero, Guicciardini) y conocidos falsarios (Annio de Viterbo); literatura de carácter decididamente italiano (Petrarca, Pietro Bembo, Guicciardini, S. Guazzo, Laura Terracina, Toscanella, Manzini, T. Caraffa, Torcuato Tasso, Ariosto, G.B. Marino, V. Malvezzi, P. Metastasio, G.F. Biondi, A. Possevino), textos políticos (S. Schiappalaria y L. Muratori); una edición veneciana de 1584 de El Cortesano de Castiglione, que se envió a la sección de prohibidos de la Universidad, etc. En fin, la preferencia por el libro italiano obedece al interés de Felipe de Castro por las artes. Los libros italianos eran también muy importantes en la biblioteca del doctor Carballo de Castro, incorporada como donación a la Universidad en 1789: este médico afincado en Madrid donó 340 títulos en 453

42 REY CASTELAO, O.: "Las donaciones ilustradas a la Biblioteca de la Universidad de Santiago", Entre Nos, Universidad de Santiago, 2001, pp. 413-437.

43 Por ejemplo, BAYARDI, O.A.: Le Antichitá de Eercolano esposte, Nápoles, 1755. 
volúmenes, muy especializados, en los que la literatura científica española ocupa la mitad de los títulos, en tanto que Francia aporta el 15\% e Italia algo más (15.9\%): $24.1 \%$ en el siglo XVI, $16.9 \%$ en el XVII, $21.3 \%$ en la primera mitad del siglo XVIII y $10.4 \%$ después de 1750 ; de Italia procedía el $18 \%$ de las obras científicas y el $11.9 \%$ de otros temas, lo que explica que el italiano fuese minoritario (3.6\%), ya que la mayor parte de los textos de ciencias estaba en latín. Seguramente en las demás donaciones recibidas por la Universidad llegaron a sus anaqueles un buen número de ediciones italianas, pero los inventarios conservados no ofrecen ese dato.

Sumando compras y donaciones, más los libros procedentes de los colegios de los jesuitas expulsados en 1767, en 1794 la biblioteca universitaria era ya un fondo importante, muy barroco en sus caracteres y de marcado tono latino: Italia y no Francia ocupaba el primer puesto entre las ediciones existentes: el 22.9\% de los títulos (1402) y el $23 \%$ de los volúmenes (2.419), en tanto que eran franceses el $18.9 \%$ de unos y el 22.9\% de otros; en realidad, sumando los libros españoles a los de esos dos países, superaban el $80 \%$ del total de los existentes en la Universidad. La evolución de estas procedencias revela la creciente presencia de libro español, aunque las ediciones extranjeras, francesas antes del final del Concilio de Trento (1563), italianas después, tienen una importancia mucho mayor que en las bibliotecas eclesiásticas - tabla 1 y 2. En el último tramo del siglo XVIII, el libro italiano desbanca al francés:

Tabla 1: Procedencia de los libros de la Universidad

\begin{tabular}{|l|c|c|c|c|c|c|}
\hline Período & \multicolumn{2}{|c|}{ España } & \multicolumn{2}{c|}{ Francia } & \multicolumn{2}{c|}{ Italia } \\
\hline & $\%$ Tts & \% Vol & \% Tts & \% Vol & \% Tts & \% Vol \\
\hline-1559 & 11.7 & 11.2 & 38.8 & 40.2 & 24.8 & 23.7 \\
\hline $1560 / 99$ & 30.4 & 27.3 & 18.9 & 19.9 & 29.7 & 29.5 \\
\hline $1600 / 49$ & 39.0 & 34.4 & 26.2 & 28.0 & 20.3 & 16.9 \\
\hline $1650 / 99$ & 34.3 & 27.7 & 22.3 & 28.8 & 25.2 & 24.6 \\
\hline $1700 / 49$ & 37.7 & 25.5 & 13.3 & 20.2 & 31.9 & 35.8 \\
\hline+1750 & 71.5 & 65.0 & 6.7 & 10.4 & 13.1 & 15.2 \\
\hline
\end{tabular}

En esta biblioteca dominada por el latín en la mitad de las ediciones $(78.6 \%$ de los volúmenes antes de $1560,45 \%$ entre 1600 y 1750, 28.4\% después), es el italiano la lengua extranjera más abundante (10.2\% de los títulos, $8 \%$ de los volúmenes frente a $6.1 \%$ y $10.6 \%$ respectivamente, en francés), pero obviamente, de Italia habían llegado muchos textos en latín. Es también una biblioteca con una parte muy numerosa de títulos $(44.5 \%)$ y volúmenes $(47.5 \%)$ de tema religioso, aunque la composición temática varía según los lugares de edición y las épocas -tabla 3-. La teología mística era española (58.8\%), 14.7\% italiana y 11.4\% francesa, la teología moral, 50.2\%, $18 \%$ y $18 \%$ en cada caso, pero la teología dogmática en su mayoría (46.8\%) proce- 
TABLA 2: Fechas de edición de los libros italianos en la Biblioteca universitaria (1794)

\begin{tabular}{|l|c|c|c|c|c|c|c|c|c|}
\hline & \multicolumn{2}{|c|}{ Total } & \multicolumn{2}{c|}{ Italia } & \multicolumn{3}{c|}{ Total } & \multicolumn{3}{c|}{ Italia } \\
\hline Años & Títs & Vols. & Tits & Vols & Años & Títs & Vols. & Tits & Vols \\
\hline-1500 & 12 & 12 & 6 & 6 & $1650 / 59$ & 189 & 310 & 38 & 65 \\
\hline $1500 / 09$ & 11 & 11 & 4 & 4 & $1660 / 69$ & 259 & 405 & 53 & 99 \\
\hline $1510 / 19$ & 51 & 61 & 14 & 16 & $1670 / 79$ & 267 & 421 & 81 & 122 \\
\hline $1520 / 29$ & 57 & 62 & 17 & 18 & $1680 / 89$ & 243 & 380 & 74 & 95 \\
\hline $1530 / 39$ & 78 & 92 & 9 & 9 & $1690 / 99$ & 174 & 261 & 39 & 56 \\
\hline $1540 / 49$ & 159 & 175 & 42 & 42 & $1700 / 09$ & 183 & 344 & 49 & 81 \\
\hline $1550 / 59$ & 212 & 236 & 52 & 59 & $1710 / 19$ & 177 & 360 & 57 & 106 \\
\hline $1560 / 69$ & 220 & 281 & 64 & 70 & $1720 / 29$ & 247 & 565 & 81 & 204 \\
\hline $1570 / 79$ & 210 & 289 & 50 & 63 & $1730 / 39$ & 299 & 816 & 94 & 306 \\
\hline $1580 / 89$ & 224 & 308 & 79 & 131 & $1740 / 49$ & 230 & 528 & 81 & 239 \\
\hline $1590 / 99$ & 175 & 217 & 53 & 59 & $1750 / 59$ & 270 & 582 & 71 & 172 \\
\hline $1600 / 09$ & 231 & 300 & 54 & 56 & $1760 / 69$ & 243 & 466 & 33 & 70 \\
\hline $1610 / 19$ & 241 & 303 & 46 & 51 & $1770 / 79$ & 391 & 663 & 22 & 35 \\
\hline $1620 / 29$ & 213 & 276 & 36 & 43 & $1780 / 89$ & 114 & 162 & 8 & 8 \\
\hline $1630 / 39$ & 148 & 229 & 31 & 47 & +1790 & 1 & 1 & -- & - \\
\hline $1640 / 49$ & 198 & 336 & 42 & 47 & Sin año & 398 & 1.011 & 21 & 73 \\
\hline
\end{tabular}

día de las prensas italianas; de estas llegaba también el 29\% de las obras de historia eclesiástica -Francia aporta una décima parte-; las ediciones de derecho canónico, compuesto sobre todo de colecciones de decretales, decisiones de la Rota y normativa canónica y su aplicación práctica a través de los tribunales eclesiásticos, eran ampliamente italianas (56.5\%), de modo que es el derecho el epígrafe más nutrido de los procedentes de aquel territorio -casi el 23\%-. En el campo civil, literatura, textos de gramática y diccionarios procedían de allí en un 36.6\% de los títulos -de Francia el 13.4\%- y, además, los textos literarios extranjeros están dominados por el italiano -168 de 464 títulos-. Ciencias, técnicas y artes, que centraron la atención en la formación de esta biblioteca desde 1772, provenían en una quinta parte en cada caso, de Francia e Italia, aunque francés e italiano eran idiomas minoritarios en este sector apoyado en el latín. En historia civil, se había conseguido reunir en 1794 un fondo considerable -cerca de mil volúmenes-, dominado por las ediciones españolas (40\%), pero una quinta parte eran italianas y casi otro tanto francesas -en historia eclesiástica, la producción italiana era mayor-. El derecho civil, como es lógico, estaba integrado en un $46 \%$ por ediciones españolas, pero las italianas, con un $41 \%$, son muy relevantes en un conjunto muy poco francés. En fin, tanto por el interés que tenía la producción en si misma como por el sistema de suministro, se creó una buena colección italiana, ortodoxa en general, o así lo revela el hecho de que en el fondo de libros prohibidos, inventariado en 1800 , entre 183 títulos, sólo un $15.5 \%$ de los anteriores 
TABLA 3: Temas de los libros italianos de la Biblioteca universitaria (1794)

\begin{tabular}{|c|c|c|c|}
\hline Tema & Títulos & \% sobre el total & $\%$ en temas \\
\hline Teología & 157 & 11.2 & 16.6 \\
\hline Derecho & 319 & 22.8 & 40.2 \\
\hline Historia & 157 & 11.2 & 22.2 \\
\hline SSPP & 10 & 0.7 & 6.9 \\
\hline Biblias & 27 & 1.9 & 8.1 \\
\hline Concilios & 35 & 2.5 & 37.6 \\
\hline Predicables & 37 & 2.6 & 11.5 \\
\hline Hagiografía & 11 & 0.8 & 23.4 \\
\hline Liturgia & 29 & 2.0 & 22.5 \\
\hline Reglas & 42 & 3.0 & 31.8 \\
\hline Doctrina & 7 & 0.5 & 18.9 \\
\hline Literatura & 170 & 12.1 & 36.6 \\
\hline Clásicos & 41 & 2.9 & 21.7 \\
\hline Gramáticas & 31 & 2.2 & 19.3 \\
\hline Retórica & 11 & 0.8 & 28.2 \\
\hline Mitología & 1 & 0.1 & 11.1 \\
\hline Artes & 69 & 4.9 & 34.8 \\
\hline Milicia & 6 & 0.4 & 26.1 \\
\hline Técnicas & 2 & 0.1 & 14.3 \\
\hline Elogios & 2 & 0.1 & 4.9 \\
\hline Economía & 4 & 0.3 & 18.2 \\
\hline Viajes & 21 & 1.5 & 44.7 \\
\hline Erudición & 12 & 0.9 & 19.4 \\
\hline Pensamiento político & 20 & 1.4 & 19.0 \\
\hline Política/derecho & 9 & 0.6 & 19.4 \\
\hline Filosofía & 28 & 2.0 & 14.1 \\
\hline Ciencias & 95 & 6.8 & 18.5 \\
\hline Otros & 49 & 3.6 & 26.6 \\
\hline Total & 1402 & 100 & 22.9 \\
\hline
\end{tabular}

a 1700 y el $2.8 \%$ de los posteriores, eran italianos, siendo mucho más numerosos los franceses y holandeses; Maquiavelo, Trajano Boccalini Gregorio Leti, P. Giannone, Castiglione, Andrea Sansovino, Pietro Sarpi, Beccaria, J.I. Burlamaqui y J. Febronio, entre otros, se incluyen en ese grupo ${ }^{44}$.

Cuando en 1772 el gobierno de Carlos III ordenó que las bibliotecas de los obispos pasasen a ser públicas, la del arzobispo Bartolomé Rajoy y Losada, fallecido poco antes, cambió de condición. Este fondo abierto a la consulta pública, fue formado por lo tanto por ese prelado, antiguo abogado de la Real Audiencia de Galicia, que hizo una buena carrera política en Madrid, a la sombra del ministro Marqués de La Ensenada, y que participó en la negociación del Concordato con el papado de Roma. Recontada la biblioteca de Rajoy en 1751 y, a efectos de lo que aquí nos interesa, de

44 Biblioteca de la Universidad de Santiago, Manuscritos, leg. 320. 
nuevo en $1772^{45}$, se revela la presencia mayoritaria de libro español, pero también que el mitrado había comprado libros italianos, de modo que la disminución galopante del libro francés a partir de 1700, fue cubierta por libros de imprentas españolas e italianas: entre los 471 títulos y 888 volúmenes existentes en 1751 , el $8.3 \%$ y $9.3 \%$ eran italianos frente a $21 \%$ y $23.2 \%$ franceses; en 1772, cuando la biblioteca se convirtió en pública, tenía 628 títulos y 1.384 volúmenes, de los que el 12.5\% y 17.3\% procedían de Italia, sin modificarse la presencia francesa en porcentajes. Es una biblioteca barroca en lo esencial, aunque por su composición es la gran etapa de las recopilaciones jurídicas civiles del absolutismo monárquico y la producción canónica postridentina, lo que llena sus anaqueles; el predominio del latín (65\% de los títulos) y del castellano, no deja espacio a los otros idiomas, entre los cuales el italiano es irrelevante, por lo razones ya dichas. Es también la biblioteca de un jurista, dominada por el derecho, canónico y civil, y, sobre todo, por las colecciones de normativa romana-decretales, bulas, decisiones de la Rota-. El peso de las ediciones italianas seguramente era mayor en la biblioteca que por entonces tenía el cabildo catedralicio compostelano, donada en 1762 por el canónigo Diego Juan de Ulloa, eclesiástico ilustrado que estudió derecho en Bolonia y vivió en Roma, en cuyos viajes por Italia y, al parecer, por Francia, se hizo con varios lotes de libros, de cuidadosa selección. Así pues, en estas dos bibliotecas institucionales, los libros llegan de la propia Italia adquiridos por gallegos en tránsito por aquel país.

En las bibliotecas monásticas y conventuales de Galicia, existía también una importante presencia italiana -aunque la francesa es mayor-, habida cuenta de que se trata de fondos con un fuerte componente religioso ( $60 \%$ de los volúmenes), aunque no eran desdeñables los libros de historia, literatura clásica, filosofía, derecho, ciencias y de artes, acumulados paulatinamente mediante los mecanismos ya mencionados, pero que por un fenómeno de capilaridad -predicación, enseñanza- impregnaron lentamente a la sociedad civil y acabaron en poder de esta tras la Exclaustración de 1833. Tomaremos como ejemplo la del monasterio benedictino de San Martín Pinario de Santiago, que tenía 7.849 títulos en 14.398 volúmenes en 1800 y era la mejor biblioteca gallega, abierta a consulta de sus fondos en 1753 y visitada con frecuencia por componentes de las elites locales y foráneas, a quienes se les facilitaban libros en préstamo, aunque los lectores más numerosos eran los propios monjes de la abadía. Por la fecha de los libros allí existentes, es una biblioteca en la que se detecta su primer despegue en la etapa de celebración del Concilio de Trento y el segundo y definitivo a partir de su final (1562), de forma que el máximo absoluto se corresponde con ediciones de 1610-1619, seguido de cerca por las de

45 Expolio del Ilmo. Don Bartolomé Rajoy y Losada, Archivo del Cabildo de Santiago, leg. 178. 
Tabla 4: Países de procedencia de los libros de San Martín Pinario

\begin{tabular}{|l|c|c|c|}
\hline Años & España & Francia & Italia \\
\hline-1560 & 14.8 & 44.1 & 16.8 \\
\hline $1560 / 99$ & 34.2 & 20.0 & 25.8 \\
\hline $1600 / 49$ & 42.4 & 23.7 & 13.0 \\
\hline $1650 / 99$ & 40.1 & 23.8 & 13.7 \\
\hline $1700 / 49$ & 39.8 & 21.4 & 17.3 \\
\hline $1750 / 99$ & 47.6 & 23.0 & 16.8 \\
\hline+1800 & 67.7 & 22.5 & 6.5 \\
\hline Sin año & 12.5 & 6.0 & 2.0 \\
\hline Total & 37.4 & 23.8 & 16.0 \\
\hline
\end{tabular}

TABLA 5: Fecha de edición de los libros italianos en San Martín Pinario

\begin{tabular}{|l|c|c|l|c|c|}
\hline Período & Títulos & Italianos & Período & Títulos & Italianos \\
\hline-1480 & 6 & 4 & $1640-9$ & 314 & 41 \\
\hline $1480-9$ & 20 & 15 & $1650-9$ & 316 & 44 \\
\hline $1490-9$ & 23 & 12 & $1660-9$ & 322 & 52 \\
\hline $1500-9$ & 20 & 8 & $1670-9$ & 339 & 43 \\
\hline $1510-9$ & 55 & 15 & $1680-9$ & 319 & 43 \\
\hline $1520-9$ & 71 & 13 & $1690-9$ & 329 & 42 \\
\hline $1530-9$ & 106 & 8 & $1700-9$ & 214 & 20 \\
\hline $1540-9$ & 180 & 18 & $1710-9$ & 215 & 21 \\
\hline $1550-9$ & 218 & 25 & $1720-9$ & 263 & 41 \\
\hline $1560-9$ & 249 & 48 & $1730-9$ & 313 & 65 \\
\hline $1570-9$ & 241 & 62 & $1740-9$ & 295 & 77 \\
\hline $1580-9$ & 338 & 115 & $1750-9$ & 299 & 64 \\
\hline $1590-9$ & 306 & 68 & $1760-9$ & 305 & 54 \\
\hline $1600-9$ & 348 & 59 & $1770-9$ & 242 & 34 \\
\hline $1610-9$ & 329 & 37 & $1780-9$ & 187 & 26 \\
\hline $1620-9$ & 313 & 37 & +1790 & 127 & 13 \\
\hline $1630-9$ & 283 & 30 & Sin año & 352 & 7 \\
\hline & & & & & \\
\hline
\end{tabular}

1580-1600; cuando se hizo el inventario de 1800, se sufrían los efectos de la crisis del propio monasterio, pero también los de de la Revolución francesa y de los controles sobre la entrada de libros extranjeros.

En San Martín se constata, como en las anteriores bibliotecas, el predominio de las ediciones españolas, seguidas en este caso por las francesas, en tanto que las italianas ocupan el tercer puesto. Sin embargo, esta distribución en porcentajes oscila mucho a lo largo del tiempo (tabla 4). 
TABLA 6: Temas de los libros italianos en la Biblioteca de San Martín Pinario (1800)

\begin{tabular}{|l|r|}
\hline Tema & $\%$ \\
\hline Teología & 15.2 \\
\hline Derecho & 27.4 \\
\hline Historia & 14.8 \\
\hline Santos Padres & 11.8 \\
\hline Biblias & 9.7 \\
\hline Concilios & 17.6 \\
\hline Predicables & 9.3 \\
\hline Oratoria & 14.0 \\
\hline Hagiografía & 8.8 \\
\hline Liturgia & 27.8 \\
\hline Reglas & 14.4 \\
\hline Doctrina & 0.6 \\
\hline Literatura & 18.9 \\
\hline Clásicos & 11.0 \\
\hline Gramáticas & 12.6 \\
\hline Ciencias & 14.0 \\
\hline Artes & 22.0 \\
\hline Arte militar & 44.0 \\
\hline Erudición & 6.7 \\
\hline Indices & 20.0 \\
\hline Filosofía & 18.5 \\
\hline Pens. Político y económico & 9.0 \\
\hline Varia & 17.6 \\
\hline
\end{tabular}

El cambio más drástico se registra a comienzos del XVI -tablas 5 y 6-: los escasos títulos anteriores a 1510 son en su mayoría $-58.5 \%$ - ediciones italianas ${ }^{46}$, en menor medida francesas -apenas una quinta parte- y españolas en menos de un diez por ciento, procediendo el resto de Alemania y Suiza. A partir de 1510, Francia pasa a ser el origen mayoritario, dominando entre 1510 y 1560 , cede desde esta fecha, desbancada por los libros españoles e italianos, se recupera levemente después de 1600 y se fija en torno a un quinto o una cuarta parte, y, en general, las proporciones de unos países y otros se estabilizan después; en total Pinario tenía casi dos mil ediciones francesas. Las casi tres mil ediciones españolas eran minoritarias antes del Concilio de Trento y más importantes después, con máximos en la última década del XVI, entre 1610 y 1620 y en los años setenta del XVII, lo que no se acomoda a la imagen negativa de la imprenta en Castilla en el seiscientos pero tampoco tendría que hacerlo

46 Entre los 53 incunables que se conservaban, 31 estaban impresos en Italia: destacaban la regla de San Jerónimo en una edición de Roma de 1486, las epístolas de Cicerón (Venecia, 1498) o la Divina Comedia de Dante en una edición de Florencia de 1481-, aunque las imprentas venecianas eran el origen de la mayoría. 
debido a los temas que interesaban a una institución religiosa ${ }^{47}$; los máximos relativos se producen en el último tercio del XVIII, tanto porque hubo un crecimiento real de la producción española, como porque esta era menos sospechosa en un período revolucionario. Las 1.261 ediciones del bloque italiano tienen su máximo absoluto una vez finalizado el Concilio de Trento, de modo que entre 1570 y 1590 supera a Francia y alcanza entre un cuarto y un tercio de las ediciones -los máximos relativos habían quedado atrás, toda vez que el libro italiano es mayoritario hasta 1510-, pero en el XVII su posición es mediocre $-10 \%$ a $15 \%$ - y sólo se recupera entre 1730 y 1760 , gracias sobre todo a las grandes colecciones de derecho canónico. Debido en gran parte al predominio de los temas religiosos y eclesiásticos, son ediciones mayoritaria y constantemente latinas, lo que sólo cede un tanto en el XVII, pero se recupera en el XVIII hasta límites superiores incluso a los del XVI; por eso mismo, el italiano es minoritario en esta biblioteca - por debajo del francés- y es que este idioma no va más allá de un tercio de las ediciones elaboradas por las imprentas italianas, y son pocas las ediciones en otras lenguas realizadas por estas, en castellano en su mayor parte y muy pocas y tardías en francés, aunque hay un buen grupo de libros en dos o varios idiomas, diccionarios por lo general (tabla 7).

Tabla 7: Idiomas de las ediciones italianas de San Martín

\begin{tabular}{|l|c|c|c|c|c|}
\hline Período & Títulos & $\%$ & Latín & Italiano & Otros \\
\hline $1470-99$ & 31 & 2.5 & -- & -- & -- \\
\hline $1500-49$ & 62 & 4.9 & 77.4 & 21.0 & 1.6 \\
\hline $1550-99$ & 318 & 25.2 & 69.4 & 27.8 & 2.8 \\
\hline $1600-49$ & 204 & 16.2 & 53.9 & 36.9 & 9.2 \\
\hline $1650-99$ & 224 & 17.8 & 55.2 & 35.0 & 9.8 \\
\hline $1700-49$ & 224 & 17.8 & 82.6 & 12.5 & 4.9 \\
\hline $1750-99$ & 189 & 15.0 & 70.4 & 17.5 & 12.1 \\
\hline+1800 & 2 & 0.1 & -- & -- & -- \\
\hline Sin año & 7 & 0.6 & 28.6 & 57.2 & 14.2 \\
\hline Total & 1261 & 100 & 67.7 & 25.4 & 6.9 \\
\hline
\end{tabular}

La producción italiana es muy dispersa en cuanto a las ciudades de origen: en San Martín hay ediciones de al menos 44 núcleos distintos, pero una buena parte procede de Venecia -593 títulos, 47\%- y de Roma-326, 25.8\%-, de modo que la primera aportó el $7.6 \%$ de las ediciones existentes - sólo la superan Madrid, París y Lyon- y la segunda el $4.1 \%$-es la sexta ciudad en el ranking general de este fondo-. De Nápoles eran sólo 65 $-5.1 \%$ de las italianas, $0.8 \%$ del total- y 32 de Turín, de modo que las demás aportaban

47 PÉLIGRY, Ch. : «Les difficultés de l'édition castillanne au XVIIe siècle ...», p. 257 
pequeños números. De Italia venían la mayor parte de los textos de arte militar y más de un tercio de las ediciones de derecho canónico -en especial, las grandes colecciones de decretales-, pero son los únicos campos en los que ocupa un primer lugar; un espacio secundario pero significativo lo tiene en textos litúrgicos. La presencia del libro italiano encaja con la evolución general de la producción tipográfica de aquel territorio: abundante antes de 1500, triunfante tras el Concilio de Trento y en decadencia lenta desde 1600 y rápida después, y marcada por el predominio veneciano -gracias a Manuzzio y Giolitto- y romano y el de los textos en latín antes del Concilio y en italiano después ${ }^{48}$.

En los contenidos temáticos, la biblioteca de San Martín era la mejor surtida de Santiago a fines del XVIII, lo que incluye un buen suministro de obras prohibidas -3,8\% en 1836-. En el mayoritario sector religioso, la teología reúne más de una quinta parte de los títulos y de los volúmenes, y se compone de ediciones españolas (43.4\%), mucho más que francesas $(22 \%)$ e italianas $(15.2 \%)$, y, a diferencia de la biblioteca de la Universidad, no hay distancias apreciables entre las distintas ramas, de modo que la aportación italiana es de una décima parte de las obras místicas, 18\% de las morales y $16.6 \%$ de las obras dogmáticas, es decir, siempre en proporciones inferiores a las francesas, sin duda por la vinculación que los benedictinos compostelanos mantenían con sus hermanos de la congregación francesa de Saint-Maur. La historia eclesiástica (3.9\% de títulos, 6.6\% de volúmenes de la biblioteca) se componía de 300 títulos y 950 volúmenes, y, de nuevo, las ediciones italianas se sitúan por debajo de las españolas y las francesas, aportando el 17.7\%. El derecho canónico representa el 3.8\% de los títulos -casi 300-y el 4\% de los volúmenes -casi seiscientosy se identifica con grandes colecciones -decretales, decisiones de la Rota, normativa canónica romana, etc.-: las ediciones italianas, predominantes en la Universidad, lo son en un orden menor, con poco más de un tercio frente al $18.3 \%$ de las españolas, $29.7 \%$ de las francesas y $18.3 \%$ de otras procedencias, y como en aquella otra biblioteca, se trata de textos en latín -86.3\%- sobre todo. Biblias, comentarios de la Biblia y textos de los Santos Padres que abarcan casi una décima parte de títulos y volúmenes, tienen a Francia como país de edición en 39.9\% de los textos bíblicos y sus comentarios y del $44.4 \%$ de los patrísticos, y en medida menor a España $-28.7 \%$ y 10.4\%-, destacando la abundancia de ediciones de los Países Bajos del Sur o de Ale-

48 Utilizamos como principal referencia la obra de SANTORO, M.: Storia del libro italiano. Libro e societá in Italia dal Quatrocento al Novecento, Milán, 1995; CAPRA, C. y otros, La stampa italiana dal Cinquecento all'Ottocento, Bari, 1976; BARBIERI, F.: Il libro italiano del seicento, Roma, 1985. INFELISE, M. : "Le librairie italiennne (XVIIe-XVIIIe)", L'Europe et le livre..., p. 68, y "La crise de la librairie vénitienne", en BARBIER, F. : Le livre et l'historien, Ginebra, 1997, p. 343; también, QUONDAM, A. : "Mercancía de honor, mercancía de utilidad. Producción del libro y trabajo intelectual en Venecia en el XVI", en PETRUCCI, A.: Libros, editores..., p. 71. 
mania; de antes de Trento hay abundantes ediciones de Venecia, pero no era esta su especialidad, lo mismo que cabría decir de las numerosísimas obras de predicación.

Entre la producción civil, las obras puramente jurídicas son italianas en una quinta parte de los casos, españolas en un cuarto y francesas en más de un tercio de las ediciones (34.4\%), distribución que difiere del derecho canónico y del pensamiento político, social y económico, en los que, bien por razones de control ideológico, bien por tratarse de traducciones, las imprentas españolas generaron el mayor número -44.7\%-, y Francia e Italia sólo el 9\% en cada caso. El derecho civil fue más importante antes del Concilio de Trento, cuando Roma todavía no producía las ingentes cantidades de normativa y de casuística que se hicieron imprimir una vez terminado aquel, y después de 1750, cuando se actualiza la biblioteca y se adquieren colecciones de derecho más moderno, como los textos de Beccaria. En el sorprendente fondo histórico de San Martín, compuesto por casi mil títulos, las ediciones españolas eran un $38 \%$, las francesas una quinta parte y las italianas casi un 14\%; la pauta está marcada por las abundantes biografías de los personajes más diversos -en especial las siempre escabrosas de Gregorio Letti- y por la influencia de las obras de Muratori, que contrapesan la presencia de falsificaciones, incluidas las de Annio de Viterbo. Tan sorprendente como el epígrafe anterior es la producción científica, que se correspondía en un $30.9 \%$ con ediciones francesas, $27.8 \%$ españolas y $14 \%$ italianas. En cuanto a los libros prohibidos, el listado realizado en 1836 recoge 461 volúmenes correspondientes a 192 títulos: entre los autores más recurrentes está Febronio, cuya revisión de los derechos de la Iglesia lo hacían sospechoso, además de Tamburino o Galiano, de quienes había más de una obra o de un ejemplar.

\section{Conclusiones}

La dificultad de captar los mecanismos comerciales por los cuales llegaban los libros y otros productos de la imprenta a territorios periféricos como Galicia, sólo en parte justifica que no se indague en esta cuestión como se merece. Si no puede ser mediante documentación escrita, sí puede ser mediante fórmulas metodológicas alternativas: el seguimiento de una obra significativa, el estudio de los lectores más necesitados - por su oficio- de libros de procedencia lejana, la indagación en los sectores mercantiles de dedicación mixta-, la detección de fórmulas poco visibles -donaciones, herencias-, o inespecíficamente comerciales -almonedas, ventas espirituales-, o, como hemos hecho aquí, la observación de un tipo de libros que por su origen material, son más difíciles de explicar que aquellos otros de trayectoria bien conocida. Ateniéndonos a esto, podemos decir que en Galicia, los numerosos obstáculos a una circulación ágil de los libros son fáciles de constatar y que por eso mismo, los 
que encontramos en casas y en instituciones tienen un sesgo que procede menos de la voluntad que de la selección impuesta por los medios de comunicación y de transporte, y las posibilidades de la información y la difusión. Para comprobarlo, hemos hecho un seguimiento de las distintas fórmulas de llegada y comercialización de los libros, optando finalmente por observar la presencia del libro italiano, del que es bien sabido que fue fundamental en las bibliotecas españolas, como se comprueba en una amplia bibliografía, pero que no ha generado la atención historiográfica que debiera haber tenido por sí misma. Aquí recogemos un conjunto de datos que la detectan esa presencia en las bibliotecas de Galicia, un territorio que carecía de comunicaciones frecuentes con Italia, pero en el que a través del clero, todo lo italiano se conocía bien. Los libros italianos llegaban a través de intermediarios de Salamanca en el siglo XVI y de Madrid en los siglos XVII y XVIII, de la misma manera que lo hacían los libros franceses, pero la diferencia estaba en que siempre fueron menos vigilados. En las bibliotecas institucionales, su importancia fue grande en todo momento, en especial porque de Italia -de Roma, más bien- venían los grandes textos religiosos y de derecho canónico, pero también de filología, literatura, historia, etc., temas esenciales en todas ellas. Pero es evidente, al comparar unas bibliotecas con otras, que los porcentajes de incidencia del libro italiano no derivan tanto de la voluntad de quienes las formaron como de lo fortuito -donaciones de libros previamente comprados en Italia- o de la oferta de los núcleos redistribuidores españoles, y, en última instancia, por lo tanto, de la capacidad de los impresores italianos de colocar sus productos en España. En definitiva, son decisivos factores exógenos que conviene no desdeñar a la hora de calibrar las posibilidades reales de suministro en ámbitos periféricos. 